\title{
the PRIMACY of the MOTHER TONGUE: ABORIGINAL LITERACY and NON-STANDARD ENGLISH
}

\section{MARGARET ZEEGERS 1 , WAYNE MUIR ${ }^{2}$ \\ \& ZHENG LIN ${ }^{1}$}

1 School of Education, University of Ballarat, pO Box 663 , Ballarat, Victoria, 3353, Australia

2 Koori Liaison Centre, University of Ballarat, PO Box 663 , Ballarat, Victoria, 3353, Australia

\section{Abstract}

This article describes Indigenous Australian languages as having a history of pejoration dating from colonial times, which has masked the richness and complexity of mother tongues (and more recently developed kriols) of large numbers of Indigenous Australians. The paper rejects deficit theory representations of these languages as being inferior to imported dialects of English and explains how language issues embedded in teaching practices have served to restrict Indigenous Australian access to cultural capital most valued in modern socio-economic systems. We go on to describe ways in which alternative perspectives where acknowledgment of rich, complex and challenging features of Indigenous Australian languages may be used by educators as empowering resources for teacher education and teaching in schools. Our paper stresses the urgency of establishing frameworks for language success within which to develop other successful learning outcomes of Indigenous Australians:

\section{Introduction}

School based education systems have been either unable or unwilling to accommodate many of the values, attitudes, codes and institutions of Aboriginal and Torres Strait Islander society. Aboriginal and Torres Strait Islander participation and achievement in education, as defined by the wider Australian society, has been limited and this in turn limited the real choices available to Aboriginal and Torres Strait Islander people in Australian society (Johnston, 1991, p. 511).

This quote would perhaps amount to not much more than a statement of the obvious, were it not part of a most serious concern in this country, that of Indigenous Australian deaths in custody. We start here for it highlights the absolute importance of the topic under consideration in this paper. It goes beyond English proficiency, beyond linguistic competence, and beyond access to higher education and employment. It really does sit within a framework of life and death issues. We do not present it as anything less.

\section{The Mother Tongue as "Motherhood" Construct}

Rampton (1990) prefers to discuss language expertise, inheritance and affiliation than mother tongue issues, suggesting they no longer apply where the whole world is becoming multilingual. Yet there are groups within this multilingual world where mother tongue considerations are carriers of identity and culture that figure prominently in elements not only of survival, but also of flourishing, thriving and growth, and the loss of these can have serious consequences. One can really only dispense with the importance of the mother tongue in the context of knowing and complicit action, because the range of options makes it desirable to do so. Where this is not the case, where the fact of the mother tongue means more than deciding which (among a number of possible languages) to select, the importance becomes greater and greater.

The mother tongue in some cases is not a "motherhood" construct - sacrosanct, inviolate, beyond question or critique. Mother tongue can be subject to blistering pejoration. That mother tongue, when it is not one of the mainstream world languages, has been variously 
described as "primitive" and "savage" (Malinowski, 1994, p. 9) even as it is characterised as having "mere phrases of politeness in use as much among savage tribes as in a European drawing room". Aboriginal Pidgin English has been subjected to the type of definition given in former times by the Encyclopaedia Britannica (cited in Fromkin, Blair \& Collins, 2000, p. 416) as "an unruly bastard jargon, filled with nursery imbecilities, vulgarisms and corruptions". Nowadays we tend to be more open to the sorts of creativity of language usage that enables pidgins and creoles to establish communicative capacities not open to peoples who do not share a common language base, but that still does not take us into a place where nonstandard world languages are respected, valued and promoted as they would be if mother tongue were a "motherhood" construct.

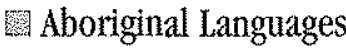

It is possible to identify 250 languages and more than 700 dialect groups among Indigenous Australians Gonas, Langton \& AIATSIS Staff, 1994), any of which may be considered as mother tongues. We could also add the Standard Australian English (SAE) dialect that derives from London and southeast England brought in from 1788 onwards as another dialect for Indigenous Australians to master, as well as non-SAEs. A spectrum of languages used by Indigenous Australians has been posited (Department of Employment, Education and Training, n.d.).The spectrum describes as light at one end the language forms in close approximation to $\mathrm{SAE}$ and heavy at the other, closer to kriol. Aboriginal Kriol, for example, spoken widely throughout northern Australia, cannot be considered one of the dialects of English, and its speakers often do not even speak Aboriginal English. We also have Pidgin English (although it cannot be considered a mother tongue), developed out of needs for establishing bases for interaction between language groups in Australian contexts.

Such development goes beyond that of negotiating day to-day relations between the dominant English language and those of Indigenous Australian groups. What is also involved is the need for coming to terms with changed circumstances with the arrival of Europeans to this country. (The English term to be used here says much about the positioning of the users - "arrival" implies a casual, almost polite visitor position; "settler" implies a positive, beneficial position; "invader" implies a harsh, brutal position; "usurper", "conqueror", and so on imply malignant positions. Perhaps none of these encapsulates the truth of the situation, but any can be applied in accordance with point of view). The fact of the pidgins and creoles in use "reflects the legacy of almost two centuries of disruption to Aboriginal Australian traditions and practices brought about by the ignorance, and at times hostility, of the dominant European society in Australia" (Fromkin et al., 2000, p. 413). An Aboriginal version, kriol, has developed in a number of areas in northern Australia. These languages operate to do different things from dialects of White speakers of English, and they cannot be considered as inferior to any of these White dialects (Christie, 1987), or "uneducated English" (Nicholls, 1994, p. 5). To do so is to adopt in part the colonial position that represents non-SAE languages in terms of the perceived superiority of SAE.

\section{Possible Mother Tongues}

There is a richness of language diversity in this country that goes largely unrecognised, even under current multicultural policies that focus on migrant languages from other parts of the world (Department of Education, Employment and Training, 2001; Halse \& Robinson, 1999). The Aboriginal languages spoken today by Indigenous Australians are linked to traditional Aboriginal and Torres Strait Islander languages, Aboriginal Kriols and Torres Strait Creole (Tripcony, 2000). In terms of Indigenous Australian languages, then, it is limiting to discuss language acquisition and development in terms of the motber tongue - motber tongues would perhaps be more appropriate. Nonetheless, Aboriginal languages do not all have the same grammatical and phonological systems. There may be similarities such as those that exist between Spanish, Portuguese and Italian, but they are not the same. Taken individually, Indigenous Australian languages have the same sorts of complex systems with elaborate and complex grammars as any European ones, and although no link has as yet been found with languages outside Australia (Jonas et al., 1994, p. 14), Indigenous Australian adults and children commonly manage proficiency in more than one. Multilingual rather than bilingual is perhaps a more apt description of Indigenous Australians. This metalinguistic skill is no mean feat given the complexity of Indigenous Australian languages. Tripcony $(2000$, p. 10$)$ gives the example of Guugu Yimithirr (in the Cooktown region), which has 11 cases, like Latin, constructed by adding different endings of nouns and pronouns.

\section{Learning English}

In 1900 , the government-appointed magistrate to the Torres Strait Islanders, John Douglas (Nakata, 1999, p. 7) reported on the people he was working with to the Royal Geographical Society of Australasia in Queensland:

They are a growing and intelligent people and they want to be educated ... They show an inclination for education which often exceeds that of our own white population ... The people are very anxious that their children should learn English because they know that their prospects will be materially assisted by their knowledge of English.

The latest census figures indicate that Indigenous Australian disadvantage in society as a whole is on the 
increase. Indeed, the current cohort of Indigenous students in higher education is only one-third the number of Indigenous Australians currently in serving custodial orders (Wright \& Burchell, 2002). Wright and Burchell $(2002$, p. 3) point out that the life expectancy of Indigenous Australians is less than the retirement age of the rest of the population and the working life is 20 years less than the national average, two factors which are significant in terms of intergenerational Indigenous Australian poverty. Indigenous Australian unemployment runs at more than $40 \%$ of all Indigenous Australian workers, only $60 \%$ are in full-time employment compared with $72 \%$ of non-Indigenous Australian workers; the Indigenous Australian combined wage average is $40 \%$ less than non-Indigenous Australians; home ownership is $31 \%$ compared with $71 \%$, and the relationship between poverty and crime is of real concern (Wright, 2002). The Indigenous Australian population is $2.4 \%$ of the total population of about 19 million, yet 1,727.4 Indigenous Australian adults per 100,000 of total population are imprisoned, compared with 115.6 per 100,000 of non-Indigenous Australians, while double the number of Indigenous Australians with university degrees $(8 \%)$ are unemployed, compared with non-Indigenous Australians (4\%) (Wright, 2002).

What has happened in the intervening years since Douglas gave his assessment of the situation? English proficiency is part of the phenomenon, inextricably linked with the Aboriginal Protectorate scheme implemented between 1904 and 1971. This has meant generations of Indigenous Austialians were educated only for village life, or menial work in rural and urban settings, deprived of any claims to full citizenship and higher education, and effectively locked out of systems of expectations and achievements taken for granted by non-Indigenous Australians. As Rose et al. (1999) point out, Indigenous Australian communities are well aware of the links between the sorts of figures we have cited and English literacy outcomes. Whole generations denied effective schooling are not so able to turn around and engage the problems generated by years of oppression and injustice. Literacy is, after all, more than learning to read and write in a given language. As Luke (1991, p. 131) argues, "literacy is inextricably tied up with questions of equality and educational opportunity, and with the distribution of political and social power - in short, with the life possibilities and social trajectories of the person who is becoming literate". Without access to the means by which cultural capital (Bourdieu \& Passeron, 1990) may be generated and increased, significant numbers of Indigenous Australian children leave schooling as beginning level readers without the skills necessary for coping with the demands of academic reading and writing, failing even to complete the years of schooling demanded in fast capitalist economies with globalising impacts on productivities.
Deficit Theory

One response to this state of affairs is to blame the home environment of Indigenous Australian children. This would mean castigating parents for choosing to speak one of their culturally-based languages, refusing to become assimilated by at least speaking English in order to give their children "the best start". Yet Australia is supposed to have moved beyond assimilation as policy for dealing with non-mainstream people in our society. It is a multicultural policy environment now, and it applies to all ethnic groups in Australia. It is possible to say that Indigenous Australian children do not have the aptitude for academic study in any case, and thus be locked into neo-colonialist discourses that have been well and truly, not to mention rightfully, debunked as utter nonsense in the present day. Gergen's (1994, p. 148) clever play on Elizabeth Barrett Browning's famous lines: "How may I fault thee? Let me count the ways" comes to mind.

Formal Commonwealth Government definition of an Indigenous Australian has three parts: where a person is an Aboriginal or Torres Strait Islander or of Aboriginal or Torres Strait Islander descent; identifies as Aboriginal or Torres Strait Islander; and/or is accepted as Aboriginal or Torres Strait Islander within their respective Aboriginal or Torres Strait Islander communities (Tripcony, 2000, p. 9). Language may be considered as one of a number of major cultural identifiers for any social group. In Victoria alone, 21,474 people identify themselves as being of Aboriginal or Torres Strait Islander origin (Department of Education, Employment and Training, 2001). To set these numbers of people up as somehow deficient, in need of being fixed in some way and set on the presumed right path, reeks of a paternalistic stance that multiculturalism fortunately no longer allows.

\section{Literacy and Language}

Another response would be to accept and validate the rich language backgrounds of Indigenous Australian children. Literacy and English language proficiency are not the same thing, regardless of current national curriculum statements that tend to conflate the two. Eades (1992) points out that $93 \%$ of Indigenous Australians use English, but these are not SAEs. They are Indigenous Australian dialects of English that fit somewhere along the spectrum that the Department of Employment, Education and Training (n.d) provides. A good reason for competence in English as well as the mother tongue is advancement in this country, however. One will find it hard to get a job without good English skills, and one will have no real academic success without it. The situation that teachers face is that not all Indigenous Australian students can be treated in the same way as they come from rich and diverse language backgrounds.

Deficit theory would demand that they drop that part of themselves, their identity as non-SAE speaking people, 
something we no longer demand even from new migrants. Wherever these languages, the mother tongues, lie along the spectrum, they are nonetheless cultural signifiers that give meaning as social beings, and this is not to be taken lightly. The Deaths in Custody statement made this quite clear. To go to deficit positions means adoption of patterns of thought and study that are not Indigenous Australian. And it means setting up conflict within the classroom the day that children enter it.

\section{Early Years Literacy Programs}

Whatever we may think of the inclusion of bureaucratically mandated and prescribed literacy activity blocks that incorporate such things as "Guided, Shared and Independent Reading" and "Writing in Early Years" literacy programs, they are premised on making the transition from home to school as smooth and trouble-free as possible for children. They take cognisance of children's emergent literacy and they build on it (Clay, 1991a, 1991b, 1993, 1998; Goodman, 1990a, 1990b; Goodman \& Burke, with Sherman, 1980). What is more, they no longer have a limited view of literacy as reading and writing. They focus on the construction of meaning from text. They look to a considerable body of research that sees this construction as being based on a grammatical system working in conjunction with phonological and graphological processing. They work with rather than in opposition to a cueing system: semantic (based on meaning), syntactic (based on sentence structures), graphophonic (based on soundletter relationships) and build classroom strategies around them. Thus, the sentence, that basic unit in all languages, is treated as containing the cues required to make sense of a text:

The girl rode her ... ("going" would not make sense here - a noun is the obvious word that has to come next).

Where the basic sentence of an Indigenous Australian language is configured differently from the basic English one, that bit of cueing information will hinder rather than help the situation. The fact is most languages' basic sentence configurations have a good deal of variation from one to another.

\section{疑 Relying on Cues}

Indeed, there is no necessary one-to-one translation or transposition of parts of speech between languages. Nicholls (1994, p. 5) has outlined some examples of this:

- The fact that many of the Indigenous Australian languages, the mother tongues, do not distinguish gender in personal pronoun usage means that sentences are constructed differently from those in English. They are incorporated into other parts of speech so that we find sentences like: "Freddie, he shoots goals".

- The English word order of subject-verb-object does not apply, so that we find sentences like: "He nothing likes, eh?"

- There is no equivalent for the English verb "to be" (and it may be worth noting how often it is dropped in pidgin forms of English as well, as being an unnecessarily complicating factor in effective basic communication) so that the sentences we find are along the lines of: "Bill walking all day long; he get tired".

- Definite and indefinite articles are not present.

- English plural forms are not used. Reduplication of the word does this: kurdu (child); kurdukurdu (children). The context is enough to tell whether the word denotes singular or plutal forms.

- The sound for "s" does not exist anyway, so English-type plural forms are out of the question (and sufferers from otitis media will not hear it expressed either).

- Lexical items do not necessarily correspond, even in Aboriginal English. Nicholls (1994, p. 5) gives the example of cheeky meaning vicious, rough, violent, or perhaps very spicy chilli sauce. English meanings of "cheeky" do not have the same connotations.

There is much more to this area of language differences, of course. The examples provided here are only the tip of the iceberg. The largest proportion of Indigenous Australians (including about 50,000 in major urban areas in Australia) speak a variety of English that is identical in almost every respect to non-Standard Australian English acquired from Anglo Australians in urban areas (Fromkin et al., 2000). Here we find, on the simplest levels, the substitution of " $f$ " or " $v$ " for the " $t$ " sound and end up hearing "mauf" for "mouth" and "muvva" for "mother". To dismiss this as some sort of inferior, uneducated version of English is to deny an intrinsically valid form of English. It is a form "governed by rules no less regular than standard languages" which "serves all the needs required of it by its community" (Fromkin et al, 2000, p. 414) with a logic as relentless as other Indigenous Australian languages which spurn the redundant plural "s" when words like "many" already tell us there is more than one.

\section{Wanguage, Status and Identity}

Correct grammar, rounded vowels and vocabulary appropriate for $\mathrm{BBC}$ or $\mathrm{ABC}$ broadcasting enunciation by themselves do not denote literacy, yet this has a profound impact on who we are, what we think and feel, and how we know what we know. Using the sort of $B B C / A B C$ language advertises an affinity with the powerful, the English-competent ones, also considered the "flash" language that puts one in a position that is a cut above the rest, as far as Indigenous Australian communities are concerned (Christie, 1987; Farrell, 1997; Fromkin et al., 2000; Tripcony, 2000). The irony of this, though, is the potential for Indigenous Australian community members 
to view their own forms of language as "rubbish language" (Farrell, 1997, p. 61) while at the same time needing them as the basis for a cultural identity that would be destroyed if they gave them up, even if they were able to do this. Heath (1994) has given us understandings of no small importance in this area, as language determines from infancy a particular way of knowing and being in the world that binds children to each other and to the adults that nurture them - the adults which the children will one day become to repeat the processes with the next generation of children.

Yunupingu $(1999$, p. 2), reflecting on his student days before he was part of Yotbu Yindi, says that for him, becoming literate meant becoming White, and becoming a Ballander teacher meant "being a Ballander teacher with aWhite face". Incidentally, as he explains it, there is no " $h$ " in his language, so that the "Hollanders" that first came to the area were dubbed "Ballanders" (Yunupingu, 2000). He also tells the story (Yunupingu, 1999) of writing an essay in his own language, Gumatj, not just to give the experience of being unable to operate academically in a foreign language to his Ballander lecturers, but also to explore deep thinking for which English was inadequate to the task. That is quite a turn around in the discourses of English language proficiency - English was not up to the task! This is an important consideration, for it underscores how the deeper regions of concepts of language, culture and identity can be ignored if we construct language in the very limiting terms of literacy alone.

\section{Beyond English Literacy - English as a Second Language and non-SAE}

It is this sort of departure - from SAE to non-SAE, based on what we know from the work done in English as a Second Language (ESL) fields, that we wish to highlight. For the purposes of this paper, we refer to skilled ESL teachers as examples of skilled non-SAE teachers. Even mainstream English literacy teachers would not consider that a Portuguese-speaking student would automatically enter a Spanish-speaking class and perform to optimum academic standards. They would even expect less of a German-speaker in that Spanish class. Yet they fail to address similar difficulties that may face Indigenous Australian students entering SAE-speaking classrooms, in spite of all the implications of the census figures (Wright, 2002; Wright \& Burchell, 2002). Different uses and functions of language in terms of embedded values, knowledges and belief systems come into play, and even on the most basic mechanistic levels such things as cueing systems will not work.

The skilled English literacy teacher is not the skilled non-SAE teacher, although there is nothing to stop that teacher from developing those skills where appropriate pedagogy is employed. The skilled mother tongue speaker is not the skilled SAE speaker where these are not the same thing, although there is nothing to stop them from developing these other language skills, where appropriate pedagogy is employed. The important thing to remember though is that learning SAE, while it usually incorporates literacy work, is not just a matter of developing literacy skills in English.

Current curriculum models may well be interpreted as models of English learning that do not take account of the needs of non-SAE students, which are quite complex. The non-SAE teacher needs to articulate not only these particular needs, but also to articulate the practices that need to be put into place to meet these needs. That is, non-SAE and literacy are not the same thing $~-$ yet current curriculum foci tend to conflate the two (Zeegers, Muir \& Lin, 2003). While literacy is undoubtedly a central issue for all students, non-SAE students have particular and distinct literacy needs. That is why we refer to literacies and not just literacy after all.

\section{图 Non-SAE Expertise}

The part that the teacher plays in non-SAE teaching and learning assumes a great deal of importance as non-SAE learners need to trust and respond to the knowledge, skills and understandings of their non-SAE teacher, who will recognise different levels of abilities, different levels and types of achievement, and plan accordingly. Planning and implementation of a non-SAE program, while it has basic connections with English teaching generally, is focused differently from mainstream English classes taught in English-speaking classrooms. A lot of research has emerged over the last few decades to help inform ESL activity, and to take issue with a lot of previous practice and protocols (see for example Kaplan, 1966; Krashen, 1987). To learn from such important work and build on it for non-SAE classroom practice would seem a worthwhile progression of scholarly and teacherly activity.

An important consideration is that of teacher expectation as far as students are concerned, and low teacher expectations of Indigenous Australian students is a recurrent theme in the literature in this area (Christie, 1987; Farrell, 1997; Nakata, 1999). Yet it would appear that the failure to take into account the knowledge that the Indigenous Australian students bring with them to school is not even acknowledged when they are treated as having English as their mother tongue.

There is little or no building on the same sort of preschool literacy skills of Indigenous Australian children in similar vein to that which is done with other children. An examination of the Early Years Literacy Program in Victorian schools (Education Victoria, 1997, p. 1) provides an example of this when it defines successful readers as those who view reading as an interactive, meaning-making process. It advises teachers to consider texts in relation to what students typically do with texts at given developmental stages, the types of texts typically encountered, in the context of the situations in which language is used and how language varies accordingly, as well as the socio-cultural influences on language that relate to expectations, values, attitudes behaviour and responses 
of people in socio-cultural contexts (Education Victoria, 1997, p. 2). It is not good enough to argue that young Indigenous Australian children do not engage in the sorts of activities described in the Victorian documents. "Text", as Christie and Mission (1998, p. 8) point out, is based on the Latin word meaning, "being woven together", and goes well beyond conceptualisations of words on paper. Texts are visual, spoken, written, painted and drawn, sung, on film, on the human body. They are the semiotics and semiosis of a culture.

\section{Reading Texts}

Indigenous Australian children enter a semiotic world as much as any other children, with history, narratives, and cultural artefacts in paintings on bark, cave walls, bodies, in the sand, and in Western-oriented communities, on paper, billboards, directional signs, and so on. Tripcony (2000, p. 11) gives us the comment of Jimmy Jampijimpa Robertson:

When some other Yapa community come and have a look at your painting there, they just talk that one, they read that one. They know which way it started and where it finished and which one is sacred site. Same as paper again. Kardiya (European, nonAboriginal, whitefella) can't read it. No. (Laughing) They got to look that paper. They got to read from a book, not from a painting.

What is more, they will interact with such texts on bases established by custom. Not all knowledge is available to all members of a culture in the same way (witness how mainstream Australia limits access to valid medical knowledge to a select group of doctors, for example), so that there is what Lindstrom (1990) has described as "narrowcasting". This is quite the opposite of "broadcasting" knowledge. We would argue therefore that the oral tradition basis of Aboriginal mother tongues as a limiting factor to literacy is a myth with which we can now safely dispense.

\section{줄 Non-SAE and Models for Academic Success}

The semiosis of Indigenous Australian culture has a solid foundation for the development of other literacies that can be employed by skilful non-SAE teachers. These teachers will work towards establishing shared bases for meaning and meaning-making, for developing shared understandings of language and language functions that form schemas for progress in academic English and attendant success in the sorts of education programs that allow equality of access for non-mainstream cultures. The very strong emphasis on visual and oral values in traditional life may be used in positive ways to empower rather than enfeeble Indigenous Australian children's engagement with English. Taplin (1996, pp. 8-9), for example, identifies cultural backgrounds in language classes for utilisation as a resource rather than as a problem, representing them as sites where background knowledge and cultures are "validated" rather than "where different discourse worlds collide".

A number of models is possible. It is possible to pick up on Yunupingu's (1999) notion of the inadequacy of the English language and go for what he considers to be the "double power" of the best of English and the best of Indigenous Australian ways to forge bilingual/multilingual models within classrooms. It is possible to consider the drawing of monolingual English speakers into the multilingual and linguistically rich world of Indigenous Australian languages. Magabala Books in Broome have published a range of works that allow this to happen. Working with the powerful tool of the picture book (which is only just coming into prominence in mainstream English literacy classrooms), the books allow for non-Indigenous Australian engagement and include helpful linguistic devices to guide such a reader. We have selected The story of the crow (Torres \& Williams, n.d.) to illustrate (Figure 1).
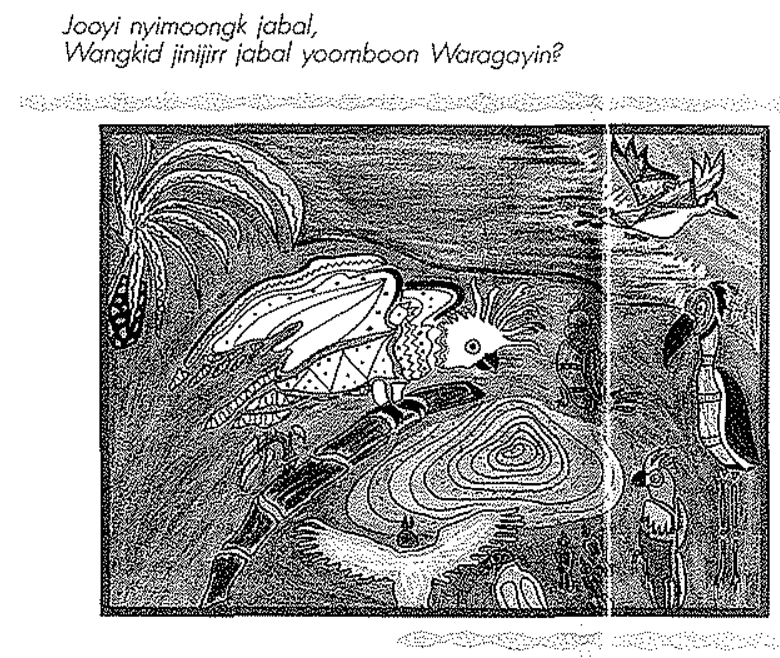

Figure 1. The story of the crow (Torres \& Williams, n.d.).

Here both languages are used, neither to the detriment of the other. There is more, however, in instructions as to how to read this non-SAE language. In doing this Torres and Williams (n.d.) are pinpointing and dealing with diversity in language that would otherwise hamper communication. Their strategy does not of itself overcome difficulties, but it embraces, acknowledges, and points a way towards overcoming them. The important word here, of course, is diversity - not superiority or inferiority of either language.

It is possible to build on this sort of text production as part of joint constructions of texts (part of a number of English literacy teaching strategies) and acknowledge the ownership of such stories as being vested within communities rather than the individual who holds the copyright, thus validating an aspect of communal cultural life. It is possible to use the Dreaming stories that share so many features of the English oral fables (Johnston, 2001a, 2001b, 2001c, 2001d; Nodelman, 1985; Saxby, 


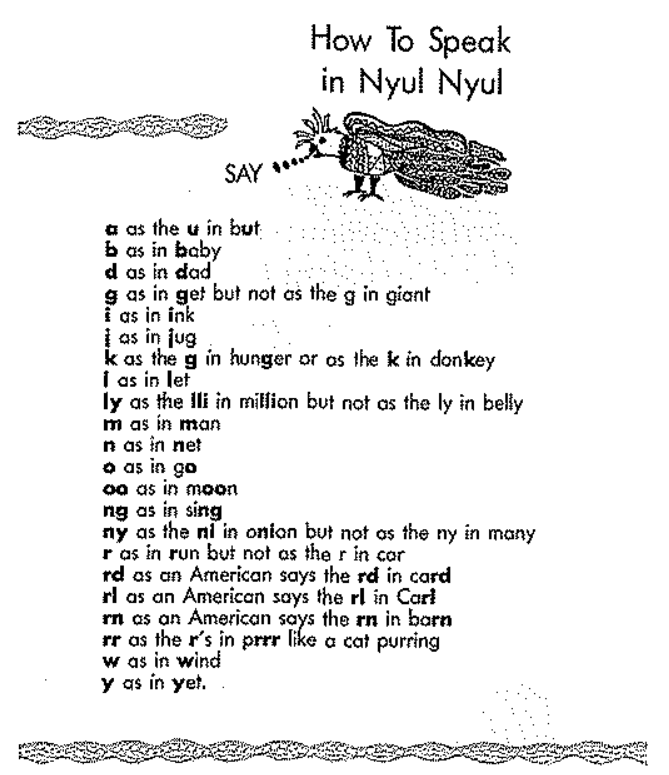

Figure 2. Example of instructional text for non-Nyul Nyul speakers of Nyul Nyul words (Torres \& Williams, n.d.).

1997; Tolkien, 1980). It is possible to identify, value and appreciate the power of joint text construction in oral forms, and the crucial roles of such constructions (Zeegers, 1996). At the same time, helpful instructions for non-Nyul Nyul speakers in the pronunciation of Nyul Nyul words serves to underscore diversity rather than superiority/inferiority concerns (Figure 2).

Research on reading comprehension in English and in ESL has grown remarkably in the past few decades, and it is possible to extrapolate from this to inform non-SAE teaching and learning programs. To probe the role that prior conceptual and cultural knowledge plays in ESL reading comprehension, schemata have been proposed to model the reader's organised prior knowledge (Bensoussan, 1998; Carrell, 1988; Fitzgerald, 1995). It may happen that a text provides nothing that has not been accounted for by the schemata already existing in the reader's mind and causes the reader to process the text in such ways as to overlook the details of the text. It is still possible that a text may happen to provide inadecuate clues to allow the reader to activate the appropriate schemata, or that a text provides the clues that allow the reader to bring in schemata that are different from, and yet compatible with, the schemata presumed by the text, resulting in different interpretations. It is also possible that readers misunderstand a text to varying degrees, ranging from minor culturally inappropriate distortions of the text, to more severe distortions that come straight from the reader's head and are not based on the text at all.

Schemata that embody readers' background knowledge about the content of culturally familiar materials facilitate the integration of local understandings and enable readers to develop a unified meaning of the text. Since reading comprehension requires the interaction between the implicit cultural knowledge presupposed by the text and the reader's own cultural background knowledge, the texts associated with familiar culture are therefore easier to understand than those that are based on less familiar and more distant cultures although they may be syntactically and rhetorically similar. Some researchers (Bensoussan, 1998; Carrell, 1988) have found that ESL readers' inadequate proficiency in English may cause them to over-rely on their prior conceptual and socio-cultural knowledge. Comparing more proficient ESL readers with less proficient ESL readers in the United States, Fitzgerald $(1995$, p. 180) concludes that:

On the whole, more proficient ESL readers (a) made better use of vocabulary knowledge, (b) used a greater variety of metacognitive strategies and used selected strategies more frequently, (c) took more action to solve miscomprehension and checked solutions to problems more often, (d) used psycholinguistic strategies that were more meaningoriented, (e) used more schema knowledge, and (f) made better and/or more inferences.

\section{Models to Learn By}

Bowman, Pascoe and Joy (1999) describe their responses to a situation where in a single classroom Burrar is taught as a first language, but the children also have one of Djinang, Gurrgoni, Gupapuyungu, Nakara, Maung, Pembatrnga, Kume, Ndjebbana, Gun-artpa as their mother tongue, with little English (that is, Aboriginal English) on starting school. These teachers set up a program based on the rich diversity of languages as resources, $a$ la Taplin (1996) and approached English as a second, third, or even fourth language to be taught and learned.

It is possible to learn from the Caribbean Academic Program (CAP) model which formally establishes Creole and English as separate languages, thereby establishing a shared understanding between teachers and students that English is a second language to be learned as such (Farrell, 1997). In such ways it would be possible to use an additive rather than a deficit model, adding SAE to language repertoire for Indigenous Australian students starting from a non-SAE base, as Farrell (1997) suggests. It is possible to build on the ESL teacher's skill repertoire to model, monitor and scaffold explicitly Indigenous Australian student achievement in English.

The CSFII English (Board of Studies, 2000, p. 6) states:

While the broad objectives of English programs will ultimately be the same for all students, those learning English as a Second Language need time, support and exposure to English before being expected to reach the learning outcomes described in the English framework, and will come to this achievement via a range of pathways ... The $E S L$ Companion to the English CSF is designed to assist teachers to cater for many ESL students by 
providing a curriculum focus and sets of learning outcomes suited to the needs of learners at different stages of English development, and by mapping a learning pathway for each of these stages.

It is possible to extend this as a framework for engaging non-SAE teaching and learning for Indigenous Australian students, invoking similar principles and strategies as appropriate to Indigenous Australian contexts.

\section{Teacher Education}

Let us be quite clear about this. There is no room for amateurs here. Tripcony $(2000$, p. 12) gives the results of a Queensland survey of teachers which indicated that only $7 \%$ of teachers felt competent about or well prepared to teach Indigenous Australian students, and even those that did had come to this state by means of their own experience rather than any form of professional development. As recently as 2001, a group of approximately 130 second and third year undergraduate $p_{1} 10$ education students at a regional university were given an article related to pedagogies and Indigenous Australian children by Halse and Robinson (1999) to consider. They were asked to identify three things that they had not known before. Without exception, they identified the statement of the importance of education for their children by Indigenous Australian parents. Every one of them had assumed that the poor performance of Indigenous Australian children was attributable to those children's parents' lack of interest in this area (Zeegers et al., 2003). Considering that this is the attitude among a cohort of the next generation of teachers in our schools, it does not augur well for the Indigenous Australian children they will have in their classrooms.

\section{留 Conclusion: Making the School-Home Connection}

Eagleson, Kaldor and Malcolm (1992, as paraphrased in Tripcony, 2000, p. 13) make perhaps the most salient observation in relation to the mother tongue:

A child's mother tongue embodies all his or her early life experiences and ingrained language habits. The mother tongue is always a cohesive linguistic system with its own grammatical/semantic properties. It allows the child to communicate, and function comfortably. It channels his or her thought processes prior to starting school.

So how do we think we ought to proceed from here? The Aboriginal Protectorate era finished in 1971. The International Year of Indigenous Peoples was 1993. The 2002 statistics do not show any appreciable change in Indigenous Australian conditions despite huge efforts towards Reconciliation and enormous goodwill displayed by a number of parties concerned in the process. We are in a hurry now. We are not looking to years of research and development to achieve the sorts of changes that are needed.We propose action based on Participatory Action Research models to facilitate this. We argue for the incorporation of non-SAE language teaching and learning to Indigenous Australian education programs at all levels, from preschool to tertiary, and at return-to-study (for mainstream Australians this may be constructed as "lifelong learning"). In all fairness to the students concerned, we cannot wait for another generation of Indigenous Australian children to grow up and into academic success. We must work with those still at school, and we must get those out of the education system back into it.

We argue for the establishment of the primacy of the mother tongue and the treatment of education in English for Indigenous Australians as non-SAE, in effect as a second or other or foreign language learning in similar vein to that delivered in the education of migrants and international students in Australian educational institutions. Working on the concept of learning success being based on language success, we argue for the establishment of a framework of language success within which to develop other successful learning outcomes of Indigenous Australians in Australian educational institutions. We see the framework as being based on the participation of Indigenous Australian education workers in the delivery of non-SAE, in partnership with classroom teachers who do not have non-SAE expertise; the development and trialling of appropriate Indigenous Australian teaching and learning materials based on non-SAE approaches; and the appropriateness or otherwise of such approaches to be tested via Participatory Action Research validation and moderation procedures and protocols.

There is already a mechanism available for the training of required education workers in the Certificate VI Workplace Assessor Training programs. There are the possibilities of flexible teacher education arrangements for speakers of Standard Australian English at IELTS 9 bands, that is, native speaker proficiency, to be accredited with Recognition of Prior Learning (RPL) as a basis for their engaging Graduate Diplomas and/or Certificates in non-SAE education. And there is a number of quality ESL teaching organisations around the country. Here may be found the sorts of English language teaching expertise that may be used to develop appropriate non-SAE classroom programs. It is possible to put some or all of this together to develop relevant and timely programs to train Indigenous Australian education workers and teachers to tackle non-SAE issues and Indigenous Australian program needs in schools. And if this is considered too much too soon, let us go back over the years when too little was done at all at any time. Let us develop that ability and willingness needed to accommodate the requirements for effective and successful Indigenous Australian student participation in our education system, just as Johnston (1991, p. 511) suggests. 


\section{References}

Bensoussan, M. (1998). Schema effects in EFL reading comprehension. Joumal of Research in Reading, 21(3), 213-227.

Board of Studies. (2000). Curriculum and standards framework ll: Engtish. Carlton: Board of Studies.

Bourdieu, P. \& Passeron, J. C. (1990). Reproduction in education, society and culture (R. Nice, Twans.). London: Sage.

Bowman, C., Pascoe, L., \& Joy, T. (1999). Literacy teaching and learning in a bilingual classroom. In P. Wignell (Ed.), Double power: English literacy and Indigenous education (pp. 61-94). Melboume: Language Australia.

Carrell, P. L. (1988). Three components of background knowledge in reading comprehension. Language Learning, 33, 183-207.

Christie, F. (1987). Language education. Geelong: Deakin University.

Christie, R, \& Mission, R. (1998). Framing the issues in literacy education. In E. Christie \& R. Mission (Eds.), Literncy and schooling (pp. 1-17). New York: Routledge.

Clay, M. M. (1991a). Becoming literate: The construction of inner control. Portsmouth, NH: Heinemann.

Clay, M. M. (1991b). Child development. In J. Flood, J. M. Jensen, D. Lapp \& J. R. Squire (Eds.), Handbook of research on teaching the language arts (pp. 40-45). New York: Macmillan.

Clay, M. M. (1993). An observation of early literacy achievement. Auckland: Heinemann.

Clay, M. M. (1998). By different paths to common outcomes. York, ME: Stenhouse Publishers.

Department of Education, Employment and Training. (2001). Guidelines for managing cultural and linguistic diversity in schools. Melbourne: Department of Education Employment and Training.

Department of Employment, Education and Training (n.d.). Langwij comes to school. Canberra: Department of Employment, Education and Training.

Eades, D. (1992). Aboriginal English and the law. Brisbane: Queensland Law Society.

Education Victoria. (1997). Keys to life: Teaching reading in the early years: Early years literacy program. South Melbourne: Longman.

Farrell, K. (1997). Bidialectalism and the potential educational status of Aboriginal English. In S. Harris \& M. Malin (Eds.), Indigenous education: Historical, moral and practical tales (pp. 59-70). Darwin: Northern Tertitory University Press.

Fitzgerald, J. (1995). English-as-a-second-language learners' cognitive reading processes: A review of research in the United States. Review of Educational Research, 65(2), 145-190.

Fromkin, V., Blair, D., \& Collins, P. (2000). An introduction to language (4th ed.). Sydney: Harcourt.

Gergen, K. J. (1994). Realities and relationsbips: Soundings in social consiruction. Cambridge, MA: Harvard University Press.

Goodman, Y. M. (1990a). Children's knowletge about literacy development: An afterword. In Y. M. Goodman (Ed.), How children construct literacy: Piagetian perspectives (pp. 115-123). Newark: International Reading Association.

Goodman, Y. M. (1990b). Discovering children's inventions of written language. In Y. M. Goodman (Ed.), How cbitdren construct literacy: Piagetian perspectives (pp. 1-11). Newark: International Reading Association.
Goodman, Y. M. \& Burke, C., with Sherman, B. (1980). Reading strategies: Focus on comprehension. New York: Holt, Rinehart and Winston.

Halse, C., \& Robinson, A. M. (1999). Towards an appropriate pedagogy for Aboriginal children. In R. Craven (Ed.), Teacbing Aboriginal studies (pp. 199-229). St Leonards, NSW: Allen \& Unwin.

Heath, S. B. (1994). What no bedtime story means: Nartative skills at home and school. In J. Maybin (Ed.), Language and hiteracy in social practice: A reader (pp. 73-95). Sydney: Department of Employment, Education and Training. Johnston, E. (1991). National report of the Royal Commission into Aboriginal deaths in custody, Vol. 2. Canberra: Australian Government Publishing Service.

Johnston, R. R. (2001a). Children's literature as a locus of literary practices. In G. Winch, R. R. Johnston, M. Holliday, L. Ljungdahl \& P. March (Eds.), Literacy: Reading, writing, and children's literature (pp. 362-371). South Melboume: Oxford University Press.

Johnston, R. R. (2001b). Fairytales: A pervasive paradigm. In G. Winch, R. R. Johnston, M. Holliday, L. Ljungdahl \& P. March (Eds.), Literacy: Reading, writing, and cbildren's literature (pp. 320-328). South Melbourne: Oxford University Press.

Johnston, R. R. (2001c). A forum: Social issues, history, fantasy. In G. Winch, R. R. Johnston, M. Holliday, L. Ljungdahl \& P. March (Eds.), Literacy: Reading, writing, and cbildren's literature (pp. 422-426). South Melbourne: Oxford University Press.

Johnston, R. R. (2001d). A locus for world community. In G. Winch, R. R. Johnston, M. Holliday, L. Ljungdahl \& P. March (Eds.), Literacy: Reading, writing, and children's hiterature (pp. 414-421). South Melbourne: Oxford University Press.

Jonas, B., Langton, M., \& AIATSIS Staff. (1994). The little red, yellow and black (and green and blue and white) book: A short guide to lndigenous Australia. Canberra: Australian Institute of Aboriginal and Torres Strait Islander Studies.

Kaplan, R. (1966). Cultural thought patterns in intercultural education. Language Leaming, 16(2), 1-20.

Krashen, S. D. (1987). Principles and practice of language acquisition. London: Prentice Hall International.

Lindstrom, L. (1990). Local knowledge systems and the South Pacific classroom. Papua New Guinea joumal of Education, 10(1), 5-17.

Luke, A. (1991). Literacies as social practices. English Education, October; 131-14.7.

Malinowski, B. (1994). The problem of meaning in primitive languages. In J. Maybin (Ed.), Language and literacy in social practice: A reader (pp. 110). Cleveden: Open University.

Nakata, M. (1999). History, cultural diversity and English language teaching. In P. Wignell (Ed.), Double power: English literacy and indigenous education (pp. 5-21). Melbotrne: Language Australia.

Nicholls, C. (1994, February). Watch your language, eh? Paper presented to Teacher Education Staff while a Visiting Fellow in Aboriginal Education, Edith Cowan University, Western Australia.

Nodelman, P. (Ed.). (1985). Touchstones: Reflections on the best in children's literature (Vol. 1). West Lafayette, IN: Children's Literature Association.

Rampton, M. (1990). Displacing the "native speaker": Expertise, affiliation, and inheritance. ELT' Joumal, 44(2), 97-101.

Rose, D., Gray, B., \& Cowey, W. (1999). Scalfolding reading and writing for Indigenous children in school. In P. Wignell (Ed.), Double power: 
English literacy and Indigenous education (pp. 23-59). Melboume: Language Australia.

Saxby, M. (1997). Books in the life of a child: Bridges to literature and leaming. Melboume: Macmillan Education Australia.

Taplin, J. (1996). Writing across a general curriculum. EA Joumal, 14(1), 8-9. Tolkien, J. R. R. (1980). Children and fairy stories. In S. Egoff, G. T. Stubbs \& L. E. Ashley (Eds.), only connect: Readings in children's literature (2nd ed., pp. 111-120). New York: Oxford University Press.

Torres, $\mathrm{P}$, \& Williams, M. (n.d.). The story of the crow. Broome: Magabala Books. Tripcony, P. (2000). Englishes and literacies: Indigenous Australian contexts. TESOL in Context, 10(2), 8-14.

Wright, J. (2002). Apartheid, Australian style. Australian Universities Review, $45(1), 36-39$.

Wright, J., \& Burchell, D. (2002). The "Indigenous issue": Introduction. Azustralian Universities Review, 45(1), 2-3.

Yunupingu, M. (1999). Double power. In P. Wignell (ed.), Double power: English literacy and Indigenous education (pp. 1-4). Melboume: Language Australia.

Yunupingu, M. (2000, September). Keynote address. Paper presented to ALARPM/PAR World Congress, University of Ballarat, Ballarat, Victoria.

Zeegers, M. (1996). Let's get critical: Observations on a non-literate text and context. Changing Education: A Joumal for Teachers and Adminisinators, 1 (March), 22-24.

Zeegers, M., Muir, W., \& Lin, Z. (2003, July). How may I marginalise thee? Let me count the ways: Indigenous Australians' languages and English literacy. Paper presented at the IFTE Conference, Melbourne.

올 About the authors

Margaret Zeegers and Zheng Lin are lecturers in the School of Education at the University of Ballarat and have considerable experience teaching and lecturing in English at a number of schools, colleges and universities in Australia and overseas.

Wayne Muir is Director of Koori Education Liaison, at the University of Ballarat and has extensive experience in developing and overseeing Indigenous Australian education projects within Australia.

All three are currently engaged in research with primary school Indigenous Australian children in the Ballarat region in their Indigenous Australian (IA) language and/or Indigenous Australian English (IAE) to research possible impacts of the teaching and learning of SAE-based literacy in primary school as part of the literacy block programs. They are investigating possible relationships between first language use and usage by Indigenous Austratian children in a provincial region, and SAE literacy. 